\title{
The mathematical crisis in secondary-tertiary transition
}

\author{
Abstract: Tertiary transition in mathematics appears to be an insurmountable struggle for \\ many students, including for high achievers in secondary school. The high dropout rates in \\ many Western Countries represent a big issue from an individual and social point of view. It \\ appears particularly significant to analyse this phenomenon in the context of the degree \\ course in Mathematics, studying students' cognitive and affective reactions to the (often \\ unexpected and severe) difficulties encountered in the tertiary transition. With this aim, we \\ developed a narrative study in a specific context in Italy - that involves excellent students \\ from secondary school - to investigate how successful and dropout students describe their \\ experience in transition. Implications for the educational practice are discussed.
}

Keywords: mathematical failure at tertiary level, high achievers, narrative research, tertiary transition in mathematics, affective factors.

\section{Introduction}

Several international data and studies describe the severe difficulties that students face in the transition to tertiary mathematics all around the world. Tertiary mathematics education has been described as "a major stumbling block in the teaching of mathematics" (De Guzmán, Hodgson, Robert \& Villani, 1998, p. 756). The high percentage of dropout undergraduate students in mathematics in several Western Countries (Rach \& Heinze, 2016) represents a big issue from an individual point of view - it causes individual psychological strain for the students involved - and from a social point of view (Rasmussen and Ellis, 2013). This phenomenon has not only an economic cost for society: the decline in the numbers of mathematics graduates and well-qualified mathematicians willing to become 
teachers is likely to reduce the quality of young people's experience of learning mathematics at school (Perkins, 2005), leading towards what Nardi (2008) calls the 'spiral of decline'.

Despite the spread and social relevance of the phenomenon, the amount of research focused on tertiary transition has been initially limited (Selden \& Selden, 2001), and only recently, tertiary transition has become a major issue in mathematics education (Gueudet, 2008). Moreover, this kind of research has been strongly influenced by the cognitive approach characterising the more general research in university mathematics (Artigue, 2016).

Essentially, something like what happened to the research about problem-solving in the '90 (Adams \& McLeod, 1989) took place: the research in the cognitive aspects of university mathematics has made great progress in recent years, but the role of affective factors in the transition difficulties has been a neglected research area. This appears to be a

critical issue in the existing research, considering that tertiary transition mathematics appears to be an insurmountable struggle also for many high achievers in secondary school: students that often seem to have important cognitive resources.

The mathematical tertiary transition is a complex phenomenon and affective aspects and their relationship with cognitive aspects are surely part of this complexity.

\section{Research in University Mathematics Education}

The earliest studies in undergraduate mathematics, characterised by a strong epistemological emphasis and a predominance of topics from Calculus/elementary Analysis, were focused on the nature of what is called advanced mathematical thinking. In particular, Tall carried out significant studies between the 1980s and the end of the millennium to describe and conceptualise different cognitive discontinuities in the transition from secondary to tertiary mathematics. On the one hand, Tall (1991) described the clear cognitive discontinuity between the two educational levels in terms of use of symbolism and 
generalisations, role of definitions, formal reasoning and proof, and level of abstraction (Hefendehl-Hebeker, Ableitinger and Herrmann, 2010, coined the evoking expression 'abstraction shock'). On the other hand, together with Vinner (Tall \& Vinner, 1981) underlined that students develop a variety of personal mental images of mathematical concepts before these concepts are formally introduced at the university level. In particular, students' mental images of crucial concepts, such as limits and continuity, are quite likely to contain factors which conflict with the formal definitions introduced at the university level. Some difficulties are therefore related to the students' need to reconceptualise forms of mathematical knowledge proved to be effective in their secondary experience (Selden, 2005). A classical example is given by the idea of equality: at the university level, students are faced with the fact that two quantities $x$ and $y$ are equal if $|x-y|<\varepsilon$ for every $\varepsilon>0$ (Artigue, 1999). More recent studies show that: on the one hand, certain reasoning strategies are inadequate when applied to university mathematics, although they might be efficient and sufficient in the kind of reasoning with specific objects required by school mathematics (Alcock \& Simpson, 2002). On the other hand, undergraduate students often interpret or produce texts drawing on everyday language patterns instead of formal mathematical language (Ferrari, 2004).

Niss (2003) underlines the need to overcome the model of self-sufficiency for universities and to develop a major communication between school and university. In particular, he stresses the problem of identity and coherence of mathematics as a subject across educational levels: for the students, the aims and characteristics of the subject, but also the rules of the game, appear to change markedly with the level and without any instructions.

On the other hand, the introduction of new mathematical topics at the university level reveals special complexities. Dorier and Sierpinska (2001) stressed how linear algebra forces connections between different languages (geometrical, algebraic, abstract) and between 
different registers of representations (graphical, algebraic, symbolic representations, tables) highlighting the students' difficulties with the coordination of different semiotic systems. Recently, some studies explore the potential of technological systems to provide multiple representations of mathematical objects and develop the coordination of different semiotic registers at the tertiary level (Bardelle \& Di Martino, 2012).

At the beginning of the new millennium - also for the increasing attention paid to the semiotic dimension of mathematical activity in educational research - there is a radical move toward a socio-cultural approach in the research in university mathematics education: "The lens is no longer directed towards the student and her cognitive functioning or development, but towards the institutional practices that condition and constrain, both explicitly and implicitly, what she has the possibility to learn or not, and the associated systems of norms and values which remain partly tacit" (Artigue, 2016, p. 17).

This socio-cultural shift emphasises the role of communication in the development of advanced mathematical thinking, but also the need to consider affective factors in transition in order to deepen our understanding of the phenomenon.

\section{The Secondary-tertiary Transition in Mathematics}

Clark and Lovric (2008), drawing on anthropological theories, present an interesting model to specifically describe the secondary-tertiary transition in mathematics: it is seen as a modern-day rite of passage for students composed of three stages: separation (from secondary school), liminal (from secondary school to university) and incorporation (into university). The rite of passage is characterised by a crisis in which the individual's routines are suddenly interrupted, changed and distorted. The transition shock is inevitable: students, academics, and teachers must acknowledge it and deal with it. 
On the one hand, Clark and Lovric describe a picture of a transition where emotions have a clear role and a definite time sequence; on the other hand, they conclude that it does not make much sense to try to simulate high school situations within a university context, because the shock can't be avoided and the rite of passage is necessary in order to master advanced mathematical thinking. Other studies confirm that lowering the level of the university lectures does not help students cope with the complexity of advanced mathematical thinking (Artigue, 2001) and may hinder the development of students as autonomous mathematical learners (De Guzmán et al., 1998).

As Gueudet (2008) observes, the students' difficulties are the central point in the studies of transition because they can indicate the existence of a transition problem. In particular, she underlines the need for identifying the causes of difficulties and for constructing a model for tertiary students' difficulties in mathematics that may form the basis for the development of appropriate actions. According to this focus, the students' point of view also appears to be very interesting: the interpretation of their own (and often unexpected) difficulties in the transition and - in extreme cases - the interpretation of their failure. For this analysis, the attribution theory developed by Weiner (1986) appears to be essential: starting with the assumption that people tend to interpret causes to an event, he analysed people's failure (or success) attributions. He recognised three main dimensions in the people's attributions: locus of control (internal vs. external); stability; controllability.

While Gueudet focuses her attention on the causes of difficulties in transitions, Rach and Heinze (2016) have a complementary approach: they try to identify the relevant variables for a successful transition at the university level. They identify five variables: interest in mathematics, self-concept as mathematics learners, prior mathematical achievement, prior mathematical knowledge, quality of learning strategies. In the case of students majoring in 
mathematics, at least the first three of these variables are, at first, usually positive. Despite that, as documented, the difficulties are still numerous, especially in the first university year, which Clark and Lovic (2008) recognised as the incorporation phase of the rite of passage represented by the tertiary transition. It is therefore particularly interesting to analyse the causes of difficulties in the mathematical transition: are they only related to the quality of mathematical knowledge and of learning strategies developed in secondary school, or due to some other factors? As discussed at the end of the previous section, we believe that the inclusion of affective factors in the picture is needed in order to catch the complexity of the phenomenon of tertiary mathematics transition. This is coherent with the modern development of the research: the deep interaction between cognition and affect and the crucial role that affective factors (emotions, beliefs and attitude) have in learning mathematics are considered, at this point, two solid findings in mathematics education (Zan, 2013; Goldin et al., 2016). On the other hand, as we have documented, some studies on tertiary transition began to consider also the role of factors such as the view of mathematics, the emotional disposition towards mathematics, and the self-concept in mathematics. These three factors represent the three dimensions that define the attitude towards mathematics in the grounded model (see Fig.1) developed by Di Martino and Zan (2010):

Figure 1

The three-dimensional model (TMA) for attitude (Di Martino \& Zan, 2010)

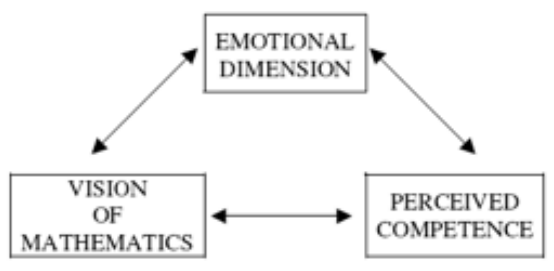

Within this framework, it appears crucial to deepen our knowledge about the role of affective factors - and in particular, of attitude in the sense of Di Martino and Zan - in the 
tertiary transition. In particular, considering tertiary transition as a rite of passage, we need to shift the attention from a static point of view (the initial state of the students) to a dynamic approach, focusing on students' attitude and failure/success attribution development during the tertiary transition. In order to approach this issue, we have developed a research project in a particular context in Italy: the Bachelor of Mathematics in Pisa.

As we have seen, several studies have been carried out from an epistemologicalcognitive perspective, while others have given voice to mathematics educators and mathematicians - sometimes comparing the two voices (Nardi, 2008). We wanted to analyse the phenomenon from the perspective of the protagonist in the transition: the students. In particular, we developed a narrative study to give voice to the students who failed in the transition and to compare their voice with that of the students who overcame the difficulties. The main claim for the use of narrative in educational research is, according to Connelly and Clandinin (1990, p. 2) that "humans are storytelling organisms who, individually and socially, lead storied lives. The study of narrative, therefore, is the study of the ways humans experience the world". In the field of mathematics education, narratives are more and more often used, especially in research about teachers' beliefs and teachers' practices. In this context, Kaasila (2007) describes different modalities for collecting narrative data: field notes of shared experiences, journal records, storytelling, letter writing, autobiographical writing, unstructured questionnaires (or interviews) that include open questions to elicit narratives.

In our research, we used a semi-structured questionnaire and a semi-structured interview to collect students' narrative about their experience in transition. Our assumption was that these instruments would have stimulated participants to explicitly evoke those events and remarks about their university experience that were important to them. Moreover, 
according to Bruner's research (Bruner, 1990), people tend to paste fragments, introducing some causal links that describe their attributions (in the sense of Wiener).

\section{Methods}

Context. The Bachelor of Mathematics in Pisa is one of the most prestigious in Italy: the majority of its students are considered excellent in mathematics during secondary school. We analysed official data from academic years 2009/10 to 2012/13: Table 1 shows the percentage of the high-rated students in the final exam of secondary school (we define high-rated marks as those between 90/100 and 100/100). Table 1 compares the situation in Pisa with the average of all Italian Bachelors of Mathematics.

Table 1

Percentage of high-rated students in the Bachelor of Mathematics: in Pisa and nationanwide

\begin{tabular}{lllll}
\hline & $2009 / 10$ & $2010 / 11$ & $2011 / 12$ & $2012 / 13$ \\
Italy & $45.0 \%$ & $42.4 \%$ & $44.5 \%$ & $40.1 \%$ \\
Pisa & $73.6 \%$ & $58.6 \%$ & $65.7 \%$ & $60.0 \%$ \\
\hline
\end{tabular}

However, as shown in Table 2, the dropout rates of the Bachelor in Pisa are close to the national average. There is obviously also an "adaptation effect": the standards in Pisa are probably higher than the standards in many other universities.

Table 2

The dropout rate among first-year students in the Bachelor of Mathematics

\begin{tabular}{lllll}
\hline & $2009 / 10$ & $2010 / 11$ & $2011 / 12$ & $2012 / 13$ \\
Italy & $24.8 \%$ & $28.4 \%$ & $19.4 \%$ & $20.8 \%$ \\
Pisa & $17.8 \%$ & $34.1 \%$ & $21.4 \%$ & $17.8 \%$ \\
\hline
\end{tabular}

The high concentration of students who are above average in terms of secondary school mathematics attainment and the presence of difficulties, as witnessed by the failure rates, make the Bachelor of Mathematics in Pisa the ideal context for our research. 
Procedure and Rationale. Two categories of students were involved: successful students i.e. students who passed the first year of the Bachelor program - and dropout students - i.e. students that left the Bachelor of Mathematics without getting their degree.

According to Artigue's suggestion (2016), our research project is founded on a multiple triangulation: methodological triangulation and investigator triangulation. For the methodological triangulation, the study was conducted in two stages. In the first stage, we created and administered an online questionnaire, structured in sections, differed for the two categories of students (successful and dropout).

- Section 1: Context information (secondary school) and personal reasons for their choices (why mathematics? Why Pisa?);

- Section 2, only for dropout students: Comparison between secondary and tertiary mathematical experience (perceived differences between secondary and tertiary mathematics, development of the relationship with mathematics in the transition, development of the self-perception in mathematics);

- Section 3: The tertiary experience with mathematics (difficulties, interpretation of the causes of difficulties, emotions related to this experience);

- Section 4: For the successful students this section was focused on their difficulties and the ways to overcome them ("Did you overcome the initial difficulties? If yes, how, and if not, why?"). For dropout students, this section was focused on the decision to quit ("Why did you leave the Bachelor of Mathematics?", "What memory do you have about your experience with mathematics at university?).

- Section 5: Conclusions and comments (free remarks, personal e-mail for those interested in the second stage of the research). 
The questionnaires had a few multiple-choice items (for example in section 1: "What kind of school did you attend? "), but, coherently with the theoretical choices, they were composed mainly of open items, used to stimulate and collect narratives (for example in section 3: "Tell us an episode of your experience you consider particularly significant"). Participation was voluntary. Students were requested to fill the questionnaire in an anonymous way. At the end of the first stage, we collected 75 responses from successful students and 52 responses from dropout students. In the last part of the questionnaire, students could share their personal e-mail address in order to take part in the second, nonanonymous, stage of the research. 27 successful students and 10 dropout students replied to the call and were effectively interviewed by the second author.

The second stage consisted of an oral and semi-structured interview developed to explore in depth the main issues raised by the two versions of the questionnaire. In particular, we investigated the role of university teachers in the students' reaction to difficulties in the transition and, depending on the category of the student, the experience of overcoming difficulties for successful students or the impact of abandoning the Bachelor on their successive experiences for dropout students. The interviews were audio-recorded.

The two-staged organisation of the research had a double motivation. Firstly, we wanted to give to the respondents the chance to answer anonymously. This method of collecting data is advocated in social science research, in order to minimise social desirability pressures (Mitchell \& Jolley, 2010) and it could be guaranteed only by the use of the questionnaire. In addition, in our case, we also considered the possible shame of dropout students in speaking openly about their failure. Furthermore, we consider the open-ended questionnaire and the interview to be two complementary instruments. Through the questionnaire, we got several dropout students involved in the research. In many cases, we 
gained their trust and interest for our research, and - thanks to the open items - we captured the authenticity, richness, depth of response, honesty and candour that are the hallmarks of qualitative data. The oral interviews allowed us to go into depth about the main issues emerging from the written data, exploiting the fact that interviews are not one-way instruments (Cohen, Manion \& Morrison, 2007).

The method of analysis. In order to analyse the qualitative data collected, we adopted the approach suggested by Demazière and Dubar (1997). Also for the analysis of the data, we proceeded with a two-stage approach. In the first stage, we developed a holistic and contentoriented approach to the data collected. The analysis of the students' experience in its entirety permitted us to highlight recurrent themes and to create categories for the second stage where we developed a categorical-content analysis. In the next section, we will discuss mainly the results of this second stage, but - in order to show the richness of the narratives collected and the approach to the data - here is an example of the first stage analysis.

\begin{tabular}{|l|c|}
\hline \multicolumn{1}{|c|}{$\begin{array}{c}\text { Original narratives (In your opinion, what is the principal } \\
\text { motivation for your dropout?) }\end{array}$} & Notes \\
\hline $\begin{array}{l}\text { I attended an "old fashioned high school", with very little } \\
\text { mathematics, the last subjects were sine and cosine. }\end{array}$ & $\begin{array}{c}\text { Mention (and probably } \\
\text { rear reflection) to the poor } \\
\text { basic preparation }\end{array}$ \\
\hline $\begin{array}{l}\text { I enrolled in the Bachelor of Mathematics in Pisa in 2009/10 } \\
\text { because I was good at maths and because I wanted to go far } \\
\text { away from home. I always did well and I thought that I would } \\
\text { make it if I studied. }\end{array}$ & $\begin{array}{c}\text { High initial perceived } \\
\text { competence in } \\
\text { mathematics }\end{array}$ \\
\hline When I arrived, the first impact was terrible. & Emotional impact \\
\hline I was in the same class of people who get bored. & Comparison with peers \\
\hline $\begin{array}{l}\text { Together with poor mathematical basis, in my case, there were } \\
\text { other motivations. I was in a couple with a very oppressive } \\
\text { guy, so I could not do group study, maybe the only thing that } \\
\text { could have helped me. }\end{array}$ & $\begin{array}{c}\text { Contingent aspect and } \\
\text { possible role of the social } \\
\text { interactions with the other } \\
\text { students }\end{array}$ \\
\hline $\begin{array}{l}\text { I went to classes, I took notes, but I didn't even understand the } \\
\text { subject. Basically, I didn't know what a function was. It is } \\
\text { knowledge that the university takes for granted, of course, but }\end{array}$ & $\begin{array}{c}\text { University gap and } \\
\text { teaching style; the black } \\
\text { hole phenomenon }\end{array}$ \\
\hline $\begin{array}{l}\text { I just had some conceptual gaps. } \\
\text { Because of my disastrous situation, I decided to focus just on } \\
\text { the algebra course, we had a test every 15 days. I thought I }\end{array}$ & $\begin{array}{c}\text { First strategies for } \\
\text { overcoming difficulties }\end{array}$ \\
\hline
\end{tabular}


could make it studying 15 days of notes at a time.

But I flunked the first and the second test. Maybe it was the wrong method or I don't know...

Failure and difficulties in

I decided to take the final exam, I focused just on that exam and didn't risk doing anything. I put off everything else. understanding the motives

In February, I took the exam, I wasn't satisfied and I didn't hand it in.

At the next exam session, I handed the exam in, I was Third (unexpected) failure, satisfied, I thought I passed it or almost passed it. I wrote 8 pages. I received a 3 out of 30 .

I will never forget it, I cried so hard.

Very strong negative

emotions associated with this repeated failure

For the first time, I wanted to do something and I didn't manage to do it.

During the second semester, there was the coding exam. I really liked the course, I was really passionate... and I received a 16 at the exam.

From that moment, I realised that I should make a choice.

Alternative strategies

Second failure

The first-time phenomenon

Fourth and different failure

Aware of the need to make a decision

All quotes are translations. We will quote the data using an alphanumeric code: $\mathrm{Q}$ and I (questionnaire/interview); D or S (dropout/successful student); a serial number.

\section{Results}

The first part of the questionnaire, besides collecting some context information, focused on the reasons for the application to the Bachelor of Mathematics. The answers to the open-ended question "Why did you enrol in the Bachelor of Mathematics?" made it possible to highlight three recurrent reasons in the answers of students in both groups (see Table 3). These three reasons were related to at least two of the three dimensions of the TMA model of attitude towards mathematics: pleasure or interest in doing mathematics; self-concept in mathematics and the ease of succeeding in maths; and the opinion of the work opportunities offered by the degree in mathematics. Only 14 answers on 127 questionnaires did not refer to any of these three motivations.

Table 3

Reason for the application to the maths bachelor 


\begin{tabular}{lll}
\hline & Successful students & Dropout students \\
Interest / like & $81.7 \%$ & $84.3 \%$ \\
Self-concept / easiness & $26.8 \%$ & $23.5 \%$ \\
Working opportunities & $11.3 \%$ & $23.5 \%$ \\
\hline
\end{tabular}

These data showed three motivations placed in different times (since the possibility to give more than one reason, the sum of the percentages, in this and other answers, could be bigger than $100 \%$ ): the pleasure and interest accrued in the past, the conviction on their own current ability in mathematics and the future projection about the potential employment opportunities offered by the maths' degree. Furthermore, it was interesting that first and second motivations related to the variables discussed by Rach and Heinze (2016). Those reasons were often reported in a single answer: "[I chose maths] because I liked it very much and because I thought I was good at it" [QD9]. The previous excerpt - and especially the use of the past tense - pointed out the possibility of evolution during university time. In particular, the evolution of the variable self-concept/easiness, at the design stage of the research, seemed to be highly significant in the study of the phenomenon of the difficulties and dropouts. For this purpose, an item in the questionnaire looked explicitly into the perception of the ability in mathematics during secondary school and the motivations for this perception: "Did you consider yourself good at maths during high school? Why?”. As expected, the majority of the students $(96.2 \%)$ stated that they considered themselves good at mathematics at the beginning of the university experience. Particularly interesting was the analysis of the reasons given to justify this belief. We mainly identified two categories: good marks obtained in secondary school (57.7\%), and the easiness of the study of mathematics and of obtaining good marks (48.1\%). Therefore, the easiness of doing mathematics, and, in particular, the little effort necessary to succeed, was a recurring index of success: "I thought I 
was good at maths because I easily succeeded. I didn't have to study a lot to understand maths" [QD18]. The impact with a different reality provoked a swirl of emotions.

The emotional dimension. From a developmental point of view, it was interesting to analyse the differences between the students' emotional disposition toward mathematics in entrance (it was the main reason for the application to the Bachelor of Mathematics), their generally negative emotions associated with the impact of the university reality (it confirmed the idea of transition as a crisis period) and their current disposition towards mathematics.

As we anticipated, strongly negative emotions were often associated with the transition experience in particular by dropout students. $75 \%$ of dropout students reported negative feelings answering the questions: "Write a feeling that is linked to your experience at the Bachelor of Mathematics". It is possible to classify these negative feelings into five categories: anxiety/distress/anguish; inadequacy/insecurity; sadness/sorrow/depression; frustration/despondency/hopelessness; fear/apprehension. While the anxiety caused by the Bachelor of Mathematics is shared with the group of successful students ("For the first two years I was in a permanent state of anxiety and distress" [QS6], "[My experience in Pisa has been] full of angst" [IS8]), sadness and sorrow characterised the group of dropout students in particular ("I remember [during that period] shedding lot of tears" [QD34]).

During the interviews, it emerged that there was an unexpected and sudden shift from a mathematical welfare to a mathematical malaise in the first encounter with mathematics at the university and that this was accompanied by negative emotions towards mathematics. The persistence of the difficulties caused a sense of helplessness, related to very strong negative emotions, contributing to fostering a downward spiral ("There were a lot of difficulties and disappointments... I felt like there was no way out" [QS29]). 
The motivations for emotions were often introduced by the following expressions: 'unexpected', 'suddenly' and 'for the first time'. A phenomenon, which we can call the firsttime phenomenon, emerged: the experience in transition for high achievers in secondary school was characterised by several 'first times': the first time that they were not the best student in math, that you are one of the many or, in the worst case, one of those having the hardest time; the first time that they understand little or nothing about what was being taught ("I remember the first day of lessons: the huge number of definitions of abstract and general objects as groups and vector spaces... I was shocked! I didn't understand where they were going with this stuff" [QS69]); the first time that you experienced failure in mathematics ("[...] I had never been in difficulty before, so I didn't know how to deal with the situation at the study level but also at the emotional level [...]" [QS69]). It was a sort of first-time syndrome.

The student identified himself as being good in maths during secondary school, and this was also recognised by people close to him (classmates, teachers, relatives). This identification was questioned suddenly and in an abrupt way during the transition. The trauma was really hard to handle in cognitive, metacognitive (what do I have to do?) and emotional terms. The first negative test scores were often associated with the feeling of shame ("I stopped talking about exams with my parents" [QS73]).

Beyond the cognitive factors, according to the dropout students' narratives, the weight of shame during the experience ("I was ashamed because sharing my difficulties meant to admit a personal defeat" [ID14]) and a sort of relief after the dropout strongly emerged ("Even three years after dropping out, my hearts races when I think of my experience in Pisa. I was not happy when I attended math lessons: I had a sense of inferiority and I was ashamed. I felt I was inadequate: that the context was not for me. My decision to drop out 
meant accepting the fact I was not capable, but also gave me a sense of freedom and serenity that I needed!" [QD48]). Vice versa, the acceptance of a new mathematical identity (Hernandez-Martinez et al., 2011) and the overcoming of emotions like shame, for example, is a distinctive aspect of successful students ("Maybe, at the beginning, the students are ashamed, or they think one needs to be at a higher level in order to ask questions during the meetings with the professor, so they don't ask questions because they feel these are silly questions. I made this mistake, but just at the beginning” [IS72]). In a certain sense, successful students proved to be able to overcome the revolution in two of the three dimensions of TMA model for attitude: the view of mathematics and the self-perception. Despite the fact that this revolution also provoked situated negative emotions, their emotional disposition towards mathematics does not change significantly. Moreover, successful students" narratives showed that the overcoming of shame was crucial to "get out of the shell" and to share the difficulties with peers. These actions distinguished the successful students' narratives from the dropouts' ones ("I made a big improvement when I started asking for help to students better than me (in this respect I was halted by pride and shame). Even now, I'm working on this respect. I try to ask as many questions as I can and, gladly, I see that they are not stupid questions (before instead, I didn't share my doubts with anyone, I was worried that they were silly doubts)" [QS6]). The relevance in the transition of what De Bellis and Goldin (2006) called affective competencies emerges: for example the ability to take frustration as a signal to modify strategy.

The analysis of the answers to the question "What has changed in your relationship with mathematics after the university experience, if something has changed?" highlighted the references to the three dimensions of attitude: emotional disposition, view of mathematics and perceived competence. In particular, it emerged that the university experience of dropout 
students has generally - and sometimes radically - changed their view of mathematics ("Surely, I realised that math is something infinite" [QD47]) and their self-perception ("Now I know I'm not as talented as I thought I was to be able to study Mathematics" [QD52]), while, in most cases, the emotional disposition towards mathematics remained positive (or anyway it returned positive after time) despite the negative experience. Only the $23,9 \%$ of the dropout students declared that the university experience negatively affected their own relationship with mathematics. Moreover, only 3 respondents $(6,5 \%$ of the sample) claimed that the emotional disposition towards mathematics was now negative in light of the university experience, even if in these cases the rejection is complete (So much changed.I developed a profound hatred for mathematics and a refusal to open any math book" [QD37]). In all other cases, the data highlighted that the emotional disposition component of attitude remained positive despite the ruinous experience ("I always like math, I became aware of my shortcomings in mathematics" [QD35]; "Nothing has changed: mathematics still fascinates $m e "[\mathrm{QD} 29])$.

The last analysed question introduced the issue of the evolution (in the transition) of the other two dimensions of attitude: the view of mathematics and the perceived competence.

\section{The evolution of the other two dimensions: the view of mathematics and the perceived}

competence. The second part of the questionnaire explored the difficulties faced by the students, firstly by comparing the difficulties encountered with those expected: on the one hand, unexpected events could provoke more intense emotions; on the other, a strong afterthought. In this case as well, as expected, both the groups of students were similar, with only slightly different percentages. In addition, it appears (see Table 4) that real difficulties encountered by the students were typically much greater than the expected ones.

Table 4 
Comparison between encountered difficulties and expected difficulties

Successful students Dropout students

$\begin{array}{lll}\text { Greater difficulties than expected } & 84.0 \% & 94.2 \% \\ \text { Difficulties as expected } & 16.0 \% & 5.8 \% \\ \text { Fewer difficulties than expected } & 0.0 \% & 0.0 \%\end{array}$

This data confirms that high school students seemed to have an incorrect perception of the gap between secondary and tertiary mathematics. According to Clark and Lovic (2008), this is one of the major causes of failure in the transition and relates to the poor communication between secondary level and university.

Besides the quantitative comparison between the expected and the encountered difficulties, the questionnaire (for both groups of students) also investigated their attributions for failure: "If you encountered difficulties, what do you think are the main causes"?

Thinking about the difficulties encountered during the university leads the students to identify different attribution for these difficulties. The narrative data collected allowed us to identify the most frequent of students' causal attributions and to organise them in five categories (not mutually exclusive): context factors, transition aspects, inadequate knowledge, inadequate way of thinking for maths and comparison with peers.

1-Context Factors. By context factors we mean the specific context of the University of Pisa, its consequent adaptation of the lessons ("Pisa has to preserve a high level, often with no regard for the students that, even if they are passionate about what they do, would need more support [...]. The professors are used to this kind of student [excellent students who seem not to be in difficulty] and make them the target of their lessons" [QS8]), and of the exams (that are considered to be more difficult than in other universities: "Sometimes one gets the impression that this university wants to keep a lot of students out, that the exam is difficult not because the exam is difficult, but because it has to be difficult" [IS10]). Although 
its contextual specificity this category revealed a more general issue: the students' perception of the difficulty or of the unwillingness of the professors to face up to the heterogeneous, even if selected, groups of students (which is a typical condition in secondary school).

2-Transition Aspects. Students stress the strong and more or less unexpected differences between secondary school and university. These differences primarily concern the object of study: the totality of dropout students claimed that the maths they found at university was really far from high school mathematics (80.77\%) or quite far (19.23\%) (“ II blame] the huge difference between the maths I studied in high school and the one in university [for the difficulties founded]" [QD25]). In the words of the students, we find the differences highlighted by the education literature (Artigue, 2016; Gueudet, 2008). These differences related to the depth of the subject and to the higher abstraction level ("[At the university there is] a higher level of abstraction. In high school, it is enough to do some calculations: there is no need for particular reasoning” [QD37], “When students arrive at university, they are not ready for the level of formalism nor of abstraction" [QS67]) and to the importance of formalism, theoretical aspects, and proofs ("more formalism and attention for proofs [is required]" [QD45]). What Niss (2003) has called the coherence problem of mathematics as a subject across educational levels is highlighted. The crucial point seems to be that the discontinuity in the subject is unexpected by the students: they choose the Bachelor of Mathematics with a clear idea of what it would be and of how good they are in mathematics, and suddenly they have to face something totally different. In the transition aspects, there are also specific didactic differences between secondary school and university, and these difficulties are often linked to the speed and to the chaining of the lessons (in fact, if you miss a lesson, it is hard to understand the next lesson and to catch up), to the requested autonomy level and to the perception of lack of interest in students' problems by the 
professors ("I was used to my small high school class, so I felt lost with teachers who cared just about the students who succeeded” [QD48]). Other studies (Di Martino \& Zan, 2011) showed that also secondary students with difficulties in mathematics often have this perception.

3-Inadequate Knowledge. About one in two students thought that the knowledge learned in the secondary school was insufficient for the university experience. They explicitly referred to the perception that they had a "poor basic preparation" [QD47] in maths and of, more drastically, that the secondary school prerequisites did not "measure up to face with this kind of bachelor" [QD48]. From our data, it emerged that students blame both secondary and university teachers for their transition difficulties. In their view, secondary school teachers did not teach them what maths really is and how it needs to be studied ("I think I was the worst and slowest in my university class. There, I understood that during five years of high school I didn't study the real maths" [QD21]), and university teachers did not pay attention to the natural difficulties in the transition ("I shifted from being kind of venerated by the teachers to a situation where the professors didn't know that I existed" [QD34]). The inadequate amount of knowledge reflected a lack of proper self-assessment ("I finished the exam, I was satisfied, I thought I passed it or almost passed it. I wrote 8 pages. I received a 3 out of 30, I will never forget it, I cried so hard" [QD34]). Incapable to self-assess seemed to have a profound impact on failure: in fact, it makes more difficult to measure the efforts needed for proper preparation.

4-Inadequate Way of Thinking for Mathematics. The 76.9\% of dropout students, on the basis of the encountered difficulties, re-evaluated their attitude in doing maths ("I started thinking that maybe I was not as good as I thought, that it had been just an illusion” [QD44]) and they identified this change of attitude as a cause of difficulty ("I didn't show as much 
thinking flexibility that I thought I had" [QD9]). Of course, the students who re-evaluated their attitude in maths changed their mind on their own mathematical ability after their first failures, and that destroyed their self-concepts ("My self-esteem definitely decreased. If you are used to certain things, like 'being good at school', and then you end up in a completely different world, it is a shock” [QD35]). This dramatic re-evaluation often led to a critical analysis of the mathematics evaluation in secondary school ("Until you are not at university, you don't realise your level in a given subject. I always had 10 in maths, I was pushed by my teacher who told me that I wouldn't have any problem” [QD2]). In particular, they claimed that what they needed to succeed in maths in secondary school was different from what was needed at university ("I keep thinking that I am good in high school maths, but the university maths seemed, to me, to be a secret language” [QD25]). The gap in the examination process, and consequently in the factors required to succeed, can be potentially very dangerous and damaging in secondary-tertiary transition because it creates dangerous illusions: "[compared to high school,] at the university you really have to study maths, and to study it, you really have to understand it" [QD12], "I realised that the rapidity of my learning [during high school] was due to the easiness of the subject and not to an above-average ability" [QD51]. The success theories constructed during secondary school (during a period of success), especially the conviction that maths ability is innate, has serious consequences. Many students thought, and continued to think, that a particular way of thinking is required to succeed in math, and that this "way of thinking for maths" is innate ("From birth you are not cut out for it, as you would need to be" [IS45]; "In high school I thought I had a strong predisposition for mathematics, but at university I understood I just had low logical ability" [QD34]). This attribution for maths success is classifiable with the dimensions described by Weiner (1986) as internal and, especially, stable and uncontrollable. The great number of 
difficulties in the transition and the belief that the way of thinking for mathematics is innate represent a devastating mix: to be good at maths you need to have an innate talent; now, with the real math, I am not good at maths; consequently, I do not have the innate talent and I cannot do anything to improve, because I am not talented. According to the students' narrations, it was one of the main causes of resignation: "I surely re-evaluated the perception of my ability and I started thinking of having little talent for the subject” [QD48]. The causal attribution (or their evolution) was one of the aspects that differentiated successful students from dropout students the most. $57.4 \%$ of the dropout students provided only external attributions, $8.5 \%$ only internal attribution, and $34 \%$ of them provided both internal and external causal attribution. Therefore, the majority of the students provided external attribution ("[I had difficulties because of] high performance was needed to pass the exam, the exam curriculums were too large and difficult" [QD8]) and in case of internal attribution, they were seen as stable and uncontrollable ("I think I do not have the right insight" [QD29], "I had difficulties because I was slow in understanding some mathematical concepts" [QD9]). On the other hand, the answers and the interviews of successful students showed that overcoming the difficulties corresponded to attributions that were unstable and controllable (89.3\% of the successful students claimed to have overcome the difficulties they found at the beginning of their university career). Realising the fact that there were some difficulties and understanding that it was possible to control or influence them was essential to overcoming these difficulties ("A lot of patience. Then, I had to admit that difficulties really existed and that they were not something that I could ignore” [QS6]).

5-Comparison with Peers. The role of the comparison with peers in the development of a new self-conception in mathematics during transition emerged clearly from the data collected (see also the example of the method section). In particular, this identification 
emerged by the answers to the following question: "In respect of the perception of your ability in mathematics, what (and why) has changed during your experience at the Bachelor if Mathematics of Pisa, if something has changed?". $17.3 \%$ of the dropout students mentioned the comparison with others as a reason for a change in self-perception. In particular, they reported that comparison with others was a disturbing factor and the perception of being the last one in the class ("I guess I was the worst and the slowest of the class” [QD21]; “At the beginning, the difficulty is mostly psychological, because you don't understand but other students perfectly understand everything” [QS52]; “I didn't understand as well as my classmates did and I didn't have their imagination” [QD9]). Sometimes, there was the belief that no one else was having trouble, and this produced strong emotions, like shame ("I always went to classes with a feeling of inferiority or shame” [QD48]).

Overcoming or not these emotions, seemed to differentiate successful students and dropout students. In fact, shame was mentioned as an inhibiting factor to spell out the difficulties, in relation to comparison with others (to professors or peers) and also to the utilisation of the learning opportunities offered by the university ("I overcame the difficulties in two ways. First of all, I went more often to the one on one meetings with the professor. [...] maybe at the beginning it can be embarrassing [...]" [IS72]). The focus on peer comparison was reinforced by the high presence of excellent students, and reflected the phenomenon known as big-fish-little-pond effect (Marsh, Trautwein, Lüdtke, Baumert \& Köller, 2007) that is typical of the mathematics universities, and highlighted one of the biggest changes for students during the secondary-tertiary transition ("After discovering that there were a lot of people who are better than me in maths, I re-evaluated the perception of my ability" [QD33]; "You immediately realise that Pisa is the place where the best Italian students in mathematics 
are concentrated. The level is very high and your self-concept is definitely questioned" [QD15]).

The comparison with others seemed to tip the balance: on the one hand, at first it gave rise to frustration and isolation (because of pride or shame), on the other hand, the students' narratives showed that belonging to a community of students appeared to be a key factor in resisting and fighting the difficulties. Sharing the difficulties with peers and attending study groups were included by $67.5 \%$ of the successful students in the reasons that enabled them to overcome the difficulties. In fact, the students' narratives showed that the credit for overcoming difficulties was mainly attributed to two factors: the commitment and efforts one made (new efforts compared to secondary school), and to sharing one's own difficulties with others (professors and peers). This last point clearly distinguished the narratives of successful students from those of dropout students. Although university teachers were explicitly mentioned in the questionnaire ("What is your opinion on your university teachers and their way of teaching?") and in the interview ("What are your memories about your university teachers?"), it was interesting that relationships and discussions with peers were perceived as crucial to overcoming difficulties, more so than that with teachers ("I overcame difficulties thanks to passion, willpower, self-criticism, time but especially thanks to the help of other student friends. Sharing my difficulties, concerns, passions with other students really helped $m e$ " [QS31]). The words that S63 said while interviewed are particularly meaningful in this respect: "I also understood that all knowledge built by myself was incomplete and lame, it lacked a fundamental part: that when I shared and compared my knowledge with others, it took on a completely different significance and substance (thus it is never an 'all mine' knowledge)". The shift from viewing oneself as part of a competitive student community to a part of a sharing community emerged as a crucial passage in the overcoming of difficulties. 


\section{Discussion and Conclusions}

First of all, we would like to discuss the methodological choices of our study. We studied the difficulties in secondary-tertiary transition using qualitative research (as many researchers successfully have, e.g. Nardi, 2008) and we gave voice to the protagonists of this rite of passage, to those who have been in difficulty. We analysed mathematical difficulties in tertiary transition from below: listening to students' voices and comparing their narratives. We believe that this approach is significant and worthy of further consideration for at least two aspects: on the one hand, the participants have the possibility of talking about the aspects they considered relevant for their own transition experience and this allows us to identify phenomenon grounded in students' experience (for example the first-time phenomenon or the significance of the comparison with peers). On the other hand, this approach allows and stimulates a posterior reflection: a reflection that did not develop during the crisis and therefore it is affected less by strong negative emotions. In this sense, it would be very interesting to compare the students' voices collected in two different moments: during the transition and at the end of the university experience.

Our study is surely affected by the particular context. This is a typical limitation of educational research at the university level (Artigue, 2016) but, in this case, the special context (of assured excellence) was specifically chosen in order to analyse the transition experience and the difficulties of high achievers in secondary school students. Our sample was almost totally composed of students considered excellent by the secondary school system standards, interested in mathematics and having sound basic knowledge.

With respect to the five variables highlighted by Rach and Heinze (2016), our study did not evaluate the students' mathematical knowledge and the quality of their learning strategies (although they were considered good and efficient in the secondary school), but 
only their perception (for example their beliefs about the adequacy of their knowledge). On the other hand, the students' narratives emphasised how all the three dimensions characterising attitude towards mathematics came into play in the transition: their view of math and their perceived level of competency were often turned upside down during the transition period, causing strong emotional reactions. University students' self-concept in mathematics is often ingrained in several previous school experiences, but our data showed it still preserves its dynamic nature. From the data, it emerged that students' self-concept evolved during the transition: the secondary-tertiary transition was a clear turning point for the mathematical self-concept of high achievers. This mathematical self-concept shift often appeared to lead to an identity crisis and to cause very strong negative emotions.

A second crucial factor emerging from our research data was the degree of evolution of students' attribution theories in their tertiary experience: we recognised a typical pattern that characterised the experience of the Bachelor of Mathematics. A high-achiever enrolled in the Bachelor of Mathematics program. Almost always, in an unexpected and abrupt manner, he faced difficulties. These difficulties were linked to strong negative emotions and were combined with a re-evaluation of the previous scholastic experience and of one's skill in math. The student produced theories of success and causal attributions: these were internal or external, but the difficulties were initially almost always perceived as uncontrollable. Up to this point in the student's path, most of the stories were similar, regardless of the interviewed student's category. But from here on there was a definite distinction between the experience of the students who abandoned the Bachelor of Mathematics and those who succeeded in continuing with his or her studies. Our study suggests that what makes the difference between dropping out and overcoming the difficulties are one's success theories and causal attributions and in particular the ability to identify controllable factors. After the first period 
of crisis, the successful students' attributions of failure typically changed and some controllable factors were recognised ("I have overcome my difficulties by changing the way I think, asking for help more often, reflecting more about my failures" (QS14]). Vice versa, the dropout students' attributions tended to remain stable in time and were often related to uncontrollable factors such as "innate predisposition" that "is needed to succeed in mathematics". This kind of attribution - that gave satisfaction to high achievers during secondary school experience - proves to be devastating when difficulties appear.

We want to conclude discussing some implications for the educational practice of our research, in order to prevent or overcome the mathematical crisis in transition. On the one hand, the university should consider the impact of the emotional aspects of students' difficulties, in particular in the case of freshmen majoring in mathematics. According to our findings, the universities could (and in our opinion, they should) organise specific support groups related to the attribution theory in mathematics, and to the acceptance of the predictable difficulties and of a possible new mathematical identity. In the light of our results, we firmly believe that this support is as important as the support related to learning strategies. On the other hand, the secondary school should be cautious to encourage success theories linked to innate factors. In fact, as we saw, these success theories can have a boomerang effect when students face their first mathematical difficulties: the student gets the idea that suddenly the lights went out and that there is nothing to do ("I started thinking that maybe I was not as good as I thought [...] perhaps maths was not my strength” [QD11]).

Other actions are suggested by what we call the 'first-time syndrome'. It appears necessary to break the first-time chain from secondary school. Giving high-achiever secondary school students the opportunity to face some challenging mathematical experiences, would allow them to work on both the emotional and the cognitive aspects. This 
is needed in order to change students' view that those who are good at maths are those who never have difficulties. Moreover, developing mathematical experiences where students feel and must overcome negative emotions in a protected environment appears necessary in order to develop crucial tools (of meta-awareness) to manage emotional difficulties in transition.

It is worth considering the hypothesis that breaking the 'first time chain' in high school could be the key to preparing students for success, or, at least, a key to giving them the intellectual tools to be more likely to overcome the unavoidable tertiary difficulties.

\section{References}

Alcock, L., \& Simpson, A. (2002). Definitions: Dealing with categories mathematically. For the Learning of Mathematics, 22(2), 28-34.

Artigue, M. (1999). The Teaching and Learning of Mathematics at the University Level Crucial Questions for Contemporary Research in Education, Notices of the AMS, 46, 1377-1385.

Artigue, M. (2001). What can we learn from educational research at the university level? In D. Holton (Ed.), The teaching and learning of mathematics at university level (pp. 207-220). Dordrecht: Kluwer.

Artigue, M. (2016). Mathematics Education Research at University Level: Achievements and Challenges. In E. Nardi, C. Winslow \& T. Hausberger (Eds.), Proc. $1^{\text {st }}$ Conf. of INDRUM (pp. 11-27). Montpellier: INDRUM.

Bardelle, C. \& Di Martino, P. (2012). E-learning in secondary-tertiary transition in mathematics: for what purpose?, ZDM - International Journal on Mathematics Education, 44(6), 787-800.

Bruner, J. (1990). Acts of meaning. Cambridge: Harvard University Press.

Clark, M., \& Lovric, M. (2008). Suggestion for a Theoretical Model for secondary-tertiary transition in mathematics. Mathematics Education Research Journal, 20(2), 25-37.

Cohen, L., Manion, L. \& Morrison, K. (2007). Research methods in education. London: Routledge.

Connelly, F. M., \& Clandinin, D.J. (1990). Stories of experience and narrative inquiry. Educational Researcher, 19(5), 2-14. 
Demazière, D. \& Dubar, C. (1997). Analyser les entretiens biographiques [Analyze biographical interviews]. Paris: Èditions Nathan.

De Bellis, V. \& Goldin, G. (2006). Affect and meta-affect in mathematical problem solving: a representational perspective. Educational Studies in Mathematics, 63(2), 131-147.

De Guzmán, M., Hodgson, B., Robert, A., \& Villani, V. (1998). Difficulties in the passage from secondary to tertiary education. In A. Louis, U. Rehmann \& P. Schneider (Eds.), Proc. of the ICM, vol. 3. Berlin, Germany (pp. 747-762).

Di Martino, P., \& Zan, R. (2010). 'Me and maths': Towards a definition of attitude grounded on students' narratives. Journal of Mathematics Teacher Education, 13(1), 27-48.

Di Martino, P., \& Zan, R. (2011). Attitude towards mathematics: A bridge between beliefs and emotions, ZDM - The International Journal on Mathematics Education, 43(4), 471-482.

Dorier, J.-L., \& Sierpinska, A. (2001). Research into the Teaching and Learning of Linear Algebra. In Holton, D. (Ed.). The teaching and learning of mathematics at university level. An ICMI Study (pp. 255-274). Dordrecht: Kluwer Academic Publishers.

Ferrari, P. L. (2004). Mathematical language and advanced mathematics learning. In M. Johnsen Høines \& A. Berit Fuglestad (Eds.), Proc. of the $28^{\text {th }}$ Conference of the IGPME (vol. 2, pp. 383-390). Bergen, Norway: PME.

Goldin, G., Hannula, M., Heyd-Metzuyanim, E., Jansen, A., Kaasila, R., Lutovac, S., Di Martino, P., Morselli, F., Middleton, J., Pantziara, M. \& Zhang, Q. (2016). Attitudes, beliefs, motivation, and identity in mathematics education. An overview of the field and future directions. Hamburg: Springer.

Gueudet, G. (2008). Investigating the secondary-tertiary transition. Educational Studies in Mathematics, 67(3), 237-254.

Hefendehl-Hebeker, L., Ableitinger, C., \& Herrmann, A. (2010). Mathematik Besser Verstehen [Mathematics better understanding]. In A. Lindmeier \& S. Ufer (Eds.), Beiträge zum Mathematikunterricht (pp.93-94). Münster: WTM-Verlag Stein.

Hernandez-Martinez, P., Williams, J., Black, L., Davis, P., Pampaka, M. \& Wake, G. (2011). Students' views on their transition from school to college mathematics: rethinking 'transition' as an issue of identity, Research in Math. Education, 13(2), 119-130.

Kaasila, R. (2007). Using narrative inquiry for investigating the becoming of a mathematics teacher, ZDM - International Journal on Mathematics Education, 39(3), 205-213. 
Marsh, H., Trautwein, U., Lüdtke, O., Baumert, J. \& Köller, O. (2007). The big-fish-littlepond effect: Persistent negative effects of selective high schools on self-concept after graduation. American Educational Research Journal, 44(3), 631-669.

Mitchell, M., \& Jolley, J. (2010). Research design explained. Belmont: WCL.

Nardi, E. (2008). Amongst Mathematicians. Teaching and learning mathematics at university level. Springer.

Niss, M. (2003). Mathematical competencies and the learning of mathematics: The Danish KOM project. In Gagatsis, A., \& Papastavridis, S. (eds.), Proc. of the $3^{\text {rd }}$ Mediterranean Conf. on Math. Ed. (pp. 115-124). Athens: Hellenic MS.

Perkins, M. (2005). If you could teach the world just one thing... Newsletter of the London Mathematical Society, 339, 31-32.

Rach, S. \& Heinze, A. (2016). The Transition from School to University in Mathematics: Which Influence Do School-Related Variables Have?, International Journal of Science and Mathematics Education, 15(7), 1-21.

Rasmussen, C. \& Ellis, J. (2013). Who is switching out of calculus and why. In A. M. Lindmeier \& A. Heinze (Eds.), Proc. of the $37^{\text {th }}$ Conference of the International Group for the Psychology of Mathematics Education (vol. 4, pp. 73-80). Kiel: PME.

Selden, A. (2005). New developments and trends in tertiary mathematics education: or, more of the same? International Journal of Mathematical Education in Science and Technology, 36(2/3), 131-147.

Selden, A., \& Selden, J. (2001). Tertiary mathematics education research and its future. In D. Holton (Ed.), The teaching and learning of mathematics at university level (pp. 237254). Dordrecht: Kluwer.

Tall, D. (1991). Advanced Mathematical Thinking. Dordrecht: Kluwer.

Tall, D. \& Vinner, S. (1981). Concept image and concept definition in mathematics with particular reference to limits and continuity. Educational Studies in Mathematics, 12(2), 151-169.

Weiner, B. (1986). An attributional theory of motivation and emotion, Springer Verlag.

Zan, R. (2013). Solid findings on students' attitudes to mathematics. EMS Newsletter, (September), 51-53. 